\title{
THE FRACTURE TOUGHNESS OF ICE IN CONTACT WITH SALT WATER
}

\author{
By S.A. SABOL and E.M. SCHULSON
}

(Thayer School of Engineering, Dartmouth College, Hanover, New Hampshire 03755, U.S.A.)

\begin{abstract}
Experiments have established that the fracture toughness of fresh-water, bubbly ice is not affected by the presence of salt water.

THIs note considers whether the resistance of ice to fast crack propagation, or the fracture toughness, is affected by water. The question arises because ice frequently breaks in the presence of water (icebergs, ice covers, and salt-water ice which contains brine-filled pores) and because surface energy, which is reduced upon wetting, is the primary barrier (Gold, 1963; Nixon and Schulson, 1987) to fast crack propagation. Earlier work along these lines (Liu and Miller, 1979) was characterized by scatter and thus did not permit a firm conclusion.
\end{abstract}

To explore this point, doubly notched cylindrical specimens of isotropic ice were employed. The double-notched configuration eliminates scatter caused by specimen-to-specimen variations. The ice from which the specimens were made was produced by flooding snow with Hanover tap water and allowing the mixture to freeze in uninsulated tubs situated within a cold room at $-10^{\circ} \mathrm{C}$. The snow had been harvested after a fresh fall during the winter of 1988. The ice was finely grained $(1-3 \mathrm{~mm})$ and bubbly. The latter characteristic was manifested by an opaque appearance and by a relatively low density $\left(880 \pm 20 \mathrm{~kg} / \mathrm{m}^{3}\right.$ vs $917 \mathrm{~kg} / \mathrm{m}^{3}$ for bubble-free, fresh-water ice). The specimens were prepared by coring cylinders $(102 \mathrm{~mm}$ diameter by $250 \mathrm{~mm})$ from the "snow" ice. Carpet-backed, phenolic end caps were bonded to the cylinders (see Lee, 1986) to allow attachment to the test machine. The specimens were then circumferentially notched to a depth of $9.91 \mathrm{~mm}$ and sharpened to an additional depth of $0.254 \mathrm{~mm}$. The sharpening was performed with a fresh razor blade held in the tool post of a lathe. The cutting was performed at $-2^{\circ} \mathrm{C}$, once the ice and the tools had reached this temperature, after which thin $(0.22 \mathrm{~mm})$ rubber sleeves were slipped over each notch. The spacing of the notches was $100 \mathrm{~mm}$ for all specimens (see Fig. 1). Subsequently, the specimens were mounted in the testing machine (a servohydraulic MTS housed within a cold-room) and lightly pre-loaded $(\approx 100 \mathrm{~N})$ for about $10 \mathrm{~s}$. Salt $(\mathrm{NaCl})$ water of salinity $35 \mathrm{ppt}$, brought into equilibrium with ice at $-2{ }^{\circ} \mathrm{C}$ by holding in its container until a thin layer of ice formed, was then injected using a "squeegy" bottle to fill the space behind one of the sleeves. The specimens were immediately loaded in tension at a constant stress-intensity rate of either $10 \mathrm{kPa} \mathrm{m}^{\frac{1}{2}} \mathrm{~s}^{-1}$ or $1000 \mathrm{kPa} \mathrm{m}^{\frac{1}{2}} \mathrm{~s}^{-1}$ until fracture. The loading times depended on the fracture toughness, but were of the order of $10 \mathrm{~s}$ at the lower rate and $0.1 \mathrm{~s}$ at the higher rate. To reduce any possible effects of time on notch acuity, sharpening was performed immediately after notching and testing was performed within a few minutes $(\sim 3-4)$ of sharpening. The sequence was completed before the next specimen was notched.

Table I summarizes the results. Of the ten specimens fractured at the lower rate, seven broke at the wet notch and three broke at the dry notch. The fracture toughnesses, respectively, were $136 \pm 25 \mathrm{kPa} \mathrm{m}^{\frac{1}{2}}$ and $134 \pm 35 \mathrm{kPa} \mathrm{m}^{\frac{1}{2}}$. Of
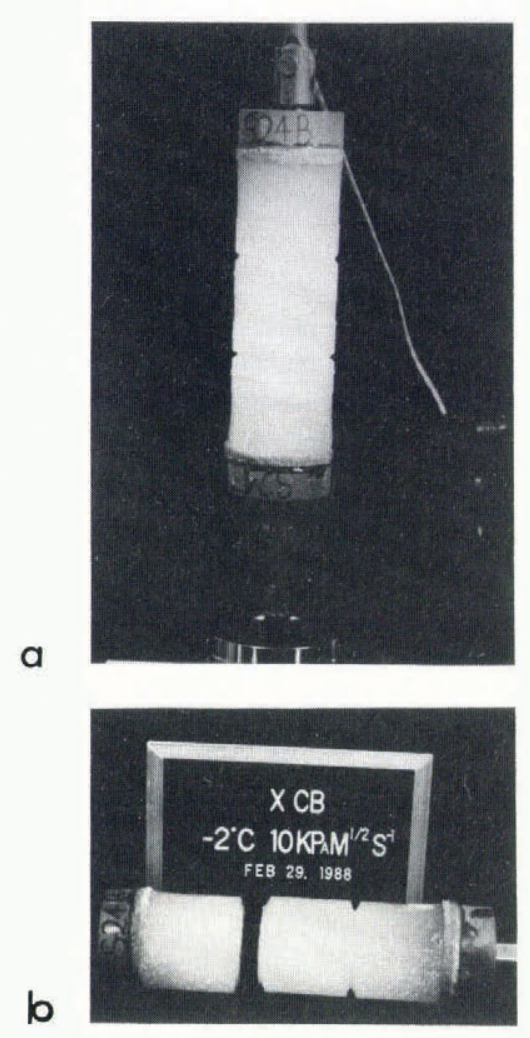

Fig. 1. Photographs showing doubly notched specimen $X C B$ (a) loaded in tension and (b) broken. Fracture occurred at the dry notch. The lcoation of the notches in this specimen is typical of the location in every specimen.

the ten specimens fractured at the higher rate, five broke at the wet notch and five broke at the dry notch. In these cases the fracture toughnesses were $82 \pm 10 \mathrm{kPa} \mathrm{m}^{\frac{1}{2}}$ and $100 \pm 9 \mathrm{kPa} \mathrm{m}^{\frac{1}{2}}$, respectively. The reduction in toughness at the higher rate reflects the behavior of bubble-free, fresh-water granular ice (Nixon and Schulson, 1987) and, as discussed in that reference, is attributed to the suppression of crack-tip creep deformation.

Examination of broken specimens under a stereographic microscope revealed little, if any, rounding of the wet notches. This observation thus renders improbable the possibility that blunting through dissolution within the notch may have compensated for a lowered toughness in the presence of the water. Observations by eye revealed a transgranular or cleavage mode of fracture.

It is concluded, therefore, that fast crack propagation through ice is not significantly affected by the presence of salt water, when the ice and the water are in equilibrium. Wetting must thus act as a post-cracking phenomenon in that the speed of its occurrence is insufficient to lower the energy barrier to propagation. 
TABLE I. THE FRACTURE TOUGHNESS AT $-2{ }^{\circ} \mathrm{C}$ OF FINELY GRAINED "SNOW" ICE

\begin{tabular}{|c|c|c|c|c|c|}
\hline Specimen & Density at $-10^{\circ} \mathrm{C}^{*}$ & Grain-size ${ }^{\dagger}$ & Stress-intensity rate & Fracture toughness & Break \\
\hline & $\mathrm{kg} / \mathrm{m}^{3}$ & $\mathrm{~mm}$ & $\mathrm{kPa} \mathrm{m} \mathrm{m}^{\frac{1}{2}} \mathrm{~s}^{-1}$ & $\mathrm{kPa} \mathrm{m}^{\frac{1}{2}}$ & $\begin{array}{l}\text { W, wet } \\
D \text {, dry }\end{array}$ \\
\hline $\mathrm{XDB}$ & - & - & 10 & 148 & W \\
\hline XBB & - & - & 10 & 125 & W \\
\hline $\mathrm{XCA}$ & - & - & 10 & 148 & W \\
\hline XDD & 900 & 1.3 & 10 & 178 & D \\
\hline $\mathrm{XBA}$ & - & - & 10 & 130 & D \\
\hline $\mathrm{XBC}$ & - & - & 10 & 106 & W \\
\hline XDC & 900 & 1.1 & 10 & 184 & W \\
\hline XCD & - & - & 10 & 133 & W \\
\hline XBD & 890 & 2.0 & 10 & 110 & W \\
\hline $\mathrm{XCB}$ & 860 & 2.2 & 10 & 93 & D \\
\hline XEA & 895 & 0.8 & 1000 & 104 & D \\
\hline XFB & 869 & 0.7 & 1000 & 82 & W \\
\hline XFD & 895 & 1.1 & 1000 & 95 & D \\
\hline XEB & 898 & 1.1 & 1000 & 92 & W \\
\hline $\mathrm{RCA}$ & 901 & 1.4 & 1000 & 91 & W \\
\hline $\mathrm{RCB}$ & 898 & 1.1 & 1000 & 72 & W \\
\hline$X X X$ & 795 & 3.0 & 1000 & 72 & W \\
\hline MF1 & - & - & 1000 & - & D \\
\hline MF2 & - & - & 1000 & 90 & D \\
\hline MF3 & - & - & 1000 & 115 & D \\
\hline
\end{tabular}

* Measured by immersing in iso-octane at $-10^{\circ} \mathrm{C}$.

+ Measured from thin sections according to the method of linear intercepts.

\section{ACKNOWLEDGEMENTS}

The authors wish to acknowledge $\mathrm{Dr} \mathrm{R}$. Johnson of Mobil Research and Development Corporation for raising the question addressed here, and the late M.G. ' Fragge and G.A. Kuehn for help with the measurements.

The work was supported by the U.S. Office of Naval Research, grant number DOD-N0014-86-K-0695, and was performed in Dartmouth's Ice Research Laboratory with additional support from the U.S. Army Research Office, U.S. Coast Guard, Mineral Management Service, Amoco, Conoco, Exxon, Mobil, Shell, and Unocal.

\section{REFERENCES}

Gold, L.W. 1963. Crack formation in ice plates by thermal shock. Can. J. Phys., 41(10), 1712-1728.

Lee, R.W. 1986. A procedure for testing cored ice under uniaxial tension. J. Glaciol., 32(112), 540-541.

Liu, H.W. and K.J. Miller. 1979. Fracture toughness of fresh-water ice. J. Glaciol., 22(86), 135-143.

Nixon, W.A. and E.M. Schulson. 1987. A micromechanical view of the fracture toughness of ice. J. Phys. (Paris), 48, Colloq. C1, 313-319. (Supplement au 3.) 